\title{
Total airway occlusion caused by an expanding bronchial foreign body
}

\author{
Manabu Suzuki 두, Ayaka Ito, Yuichiro Takeda, Masayuki Hojo
}

Department of Respiratory Medicine, National Center for Global Health and Medicine, Shinjuku-ku, Japan

\section{Correspondence to Dr Manabu Suzuki; manabu@nms.ac.jp}

Accepted 5 June 2021

\section{DESCRIPTION}

A 74-year-old man was transferred to our hospital following loss of consciousness and a 1-month history of anorexia. He underwent lung lobectomy 3 years before the current presentation because of lung carcinoma (T2N1M0). He was initially treated with antibiotics for aspiration pneumonia and his condition improved. Laxatives were administered for severe constipation. He developed dyspnoea the next morning, and despite receiving oxygen through a $15 \mathrm{~L}$ oxygen reservoir mask, his oxygen saturation level decreased to under 90\%.

We initially suspected a massive pulmonary thromboembolism; however, on chest CT, he demonstrated a highly dense, club-like structure trapped in the lower portion of the truncus intermedius (figure 1A,B).

We diagnosed the patient with foreign body aspiration and performed an emergent bronchoscopy following administration of a topical anaesthetic and transtracheal injection of $2 \%$ lidocaine. As the patient began to desaturate, we provided assisted ventilation using a Jackson-Rees circuit; unfortunately, his oxygen desaturation worsened. As he had previously undergone a right upper lobectomy, he could not breathe because his right bronchus intermedius was totally occluded. He developed a ventilation-perfusion mismatch, with an oxygen saturation level $<50 \%$. We advanced the bronchoscope to the back to observe the lumen and noted white-coloured atherosclerotic material in the right middle trunk (figure 2A,B). The foreign body was immediately removed.

Although the foreign body was too soft and brittle to be removed using ordinary biopsy forceps or a curette, we successfully removed it with alligator forceps (figure 2C,D). After removing the foreign body, his oxygen saturation level improved, and his supplemental oxygen needs decreased. Pathological

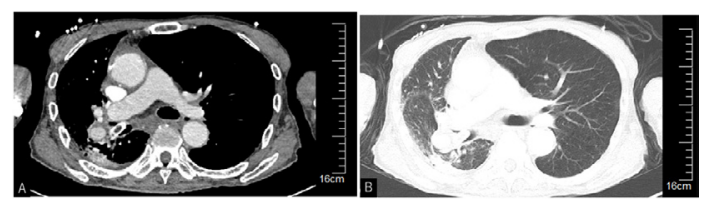

Figure 1 CT findings. (A) Axial view CT image shows that the highly dense, club-like, $20 \times 10 \mathrm{~mm}$ foreign body was trapped in the lower portion of the truncus intermedius. Peripheral infiltration is shown in the right S6 area. CT values: the radiodensities of the hyperdense and hypodense area's were approximately 180-200 and 50 Hounsfield units, respectively. (B) Axial view CT image shows peripheral infiltration in the right $\mathrm{S} 6$ area.
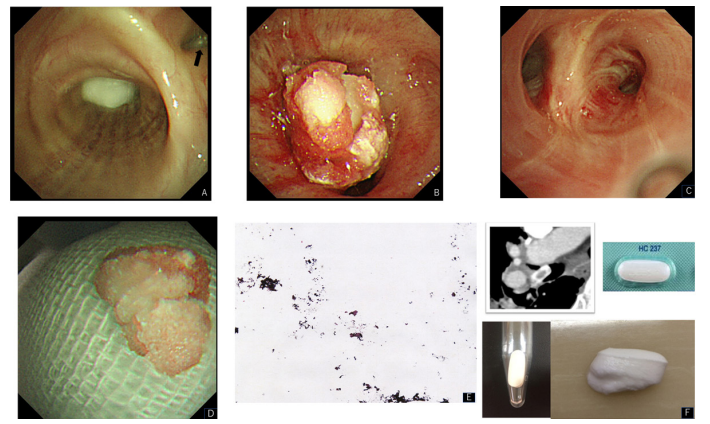

Figure 2 Bronchoscopy and pathological findings. (A, B) When the bronchoscope was advanced to the back and the lumen was observed, white-coloured atherosclerotic material was observed in the right middle trunk. Arrow points to the right upper lobe, postoperative state. (C) After removal, the right middle and lower lobe bronchi were visible. (D) The foreign body expanded because of the absorption of airway moisture and local anaesthesia. (E) Pathological analysis shows the presence of calcium (H\&E staining, $\times 40$ magnification). ( $F$ ) The size of the calcium polycarbophil tablet is $20 \times 10 \mathrm{~mm}$. After contact with water drops, the tablet absorbs the liquid, expands and becomes soft.

analysis showed that the foreign body contained calcium (figure 2E) and we determined it was a calcium polycarbophil tablet (figure $2 \mathrm{~F}$ ), prescribed to treat irritable bowel syndrome.

The presence of foreign bodies in airways is potentially life-threatening; flexible and rigid bronchoscopy are the cornerstone techniques for diagnosing and treating such patients. The nature of the foreign body will vary depending on the individual's lifestyle, religion and place of residence. Most foreign bodies comprise organic material, such as nuts and seeds in children and food and bones in adults. ${ }^{1}$ Some organic foreign bodies can expand due to bronchial secretions, thereby worsening the obstruction.

\section{Learning points}

- Foreign body in the airways can be a potentially life-threatening event.

- Polycarbophil calcium tablet can absorb moisture and expand, resulting in airway obstruction and possible suffocation.

- For elderly patients, it is important to be cautious during swallowing tablets to avoid the accidental aspiration into the airway, which can be fatal. 
There have been only a few reports of airway blockage caused by a calcium polycarbophil tablet. ${ }^{2}$ A calcium polycarbophil tablet can absorb liquid, expand and soften (figure $2 \mathrm{~F}$ ); if aspirated into the airway, it may absorb moisture from airway secretions and expand, occluding the bronchus and rendering peripheral ventilation non-effective. Patients should be careful while swallowing tablets to avoid accidental aspiration, given that foreign bodies like tablets can obstruct the airway and lead to suffocation.

Acknowledgements The authors thank Editage (https://www.editage.jp/) for English language editing.

Contributors MS and Al managed the patient. MS wrote the manuscript, reviewed the records, edited, and approved the final version. Al, YT and MH contributed to writing the manuscript and approved the final version. All authors have approved the version of the manuscript submitted for publication.

Funding The authors have not declared a specific grant for this research from any funding agency in the public, commercial or not-for-profit sectors.

Competing interests None declared.

Patient consent for publication Obtained.

Provenance and peer review Not commissioned; externally peer-reviewed.

\section{ORCID iD}

Manabu Suzuki http://orcid.org/0000-0001-8515-6466

\section{REFERENCES}

1 Tan HK, Brown K, McGill T, et al. Airway foreign bodies (FB): a 10-year review. Int $\mathrm{J}$ Pediatr Otorhinolaryngol 2000;56:91-9.

2 Enokido T, Shibuya H, Osamura K, et al. Polycarbophil calcium lodged in the bronchus. Intern Med 2017:56:2075-6.

Copyright 2021 BMJ Publishing Group. All rights reserved. For permission to reuse any of this content visit

https://www.bmi.com/company/products-services/rights-and-licensing/permissions/

BMJ Case Report Fellows may re-use this article for personal use and teaching without any further permission.

Become a Fellow of BMJ Case Reports today and you can:

- Submit as many cases as you like

- Enjoy fast sympathetic peer review and rapid publication of accepted articles

- Access all the published articles

Re-use any of the published material for personal use and teaching without further permission

\section{Customer Service}

If you have any further queries about your subscription, please contact our customer services team on +44 (0) 2071111105 or via email at support@bmj.com.

Visit casereports.bmj.com for more articles like this and to become a Fellow 